\title{
UPAYA MENINGKATKAN KOMPETENSI PENYUSUNAN RPP BERKARAKTER MELALUI PRAKTIK UNJUK KERJA
}

\author{
Sareh Joko Pitoyo \\ SD Negeri 3 Baturetno \\ jokopitoyosareh@gmail.com
}

\begin{abstract}
Abstrak
Penelitian ini bertujuan untuk meningkatkan Kompetensi guru dalam menyusun RPP Berkarakter melalui praktik unjuk kerja. Penelitian ini berbentuk Penelitian Tindakan Sekolah (PTS) yang dilaksanakan dalam 2 (dua) siklus. Lokasi penelitian ini yaitu di SD Negeri 7 Baturetno dengan subjek penelitian semua guru yang berjumlah 8 orang. Penilaian Kemampuan Guru dilakukan dengan teknik observasi dengan lembar observasi. Validasi data dilakukan dengan teknik triangulasi. Pengumpulan data dilakukan melalui observasi. Analisis data dilakukan dengan teknik analisis deskriptip komparatif. Pada kondisi prasiklus, hanya 2 orang guru $(25,0 \%)$ yang masuk predikat Baik dengan nilai rata-rata kompetensi guru hanya 61,3 (predikat Cukup). Meningkat pada siklus I menjadi 2 orang $(25,0 \%)$ yang masuk predikat Amat Baik, 4 orang guru $(50,0 \%)$ yang masuk predikat Baik dengan nilai rata-rata kompetensi guru adalah 78,8 (predikat Baik), dan meningkat lagi pada siklus II menjadi 3 orang guru $(37,5 \%)$ yang masuk predikat Amat Baik, sebanyak 6 orang guru $(62,5 \%)$ yang masuk predikat Baik dengan nilai rata-rata kompetensi guru 90,0 (predikat Baik). Berdasarkan hasil tersebut maka dapat disimpulkan bahwa praktik unjuk kerja dapat meningkatkan Kompetensi Penyusunan RPP Berkarakter Tahun Pelajaran 2019 /2020.
\end{abstract}

Kata kunci: Kompetensi guru, RPP, Praktik unjuk kerja

\begin{abstract}
This study aims to improve teacher competence in preparing character lesson plans through performance practices. This research was in the form of School Action Research (PTS) which was carried out in 2 (two) cycles. The location of this research is SD Negeri 7 Baturetno with all 8 teachers as the subject of research. Teacher Ability Assessment is done by observation techniques with observation sheets. The data validation was done by using triangulation technique. Data collection was carried out through observation. Data analysis was performed using comparative descriptive analysis techniques. In the precycle condition, only 2 teachers (25.0\%) entered the Good predicate with an average teacher competency score of only 61.3 (Sufficient predicate). Increased in the first cycle to 2 people (25.0\%) who were included in the Very Good predicate, 4 teachers (50.0\%) who were included in the Good predicate with an average score of teacher competence was 78.8 (Good predicate), and increased again in the second cycle there were 3 teachers (37.5\%) who were included in the Very Good predicate, as many as 6 teachers (62.5\%) were in the Good predicate with an average teacher competency score of 90.0 (Good predicate). Based on these results, it can be concluded that the practice of performance can increase the Competence of Preparing Characteristic RPPs for the 2019/2020 Academic Year.
\end{abstract}

Keywords: teacher competence, lesson plans, performance practice

\section{PENDAHULUAN}

Berdasarkan Undang-Undang Nomor 14 Tahun 2005 tentang Guru dan Dosen mengemukakan bahwa guru adalah pendidik profesional dengan tugas utama mendidik, mengajar, membimbing, mengarahkan, melatih, menilai, dan mengevaluasi peserta didik pada pendidikan anak usia dini jalur pendidikan formal, pendidikan dasar, dan pendidikan menengah. Guru di tuntut selalu membuat perencanaan dalam kegiatan pembelajarannya. Tidak ada alasan mengajar di kelas tanpa perencanaan pembelajaran. Perencanaan pembelajaran di kelas dikenal dengan istilah RPP. RPP 
berperan untuk mengarahkan suatu proses pembelajaran agar dapat menghantarkan peserta didik kepada tujuan pendidikan yang telah ditargetkan.

Pemahaman guru tentang kurikum akan berpengaruh pada rancangan pembelajaran di kelas. Pembelajaran harus memberikan kesempatan yang luas kepada peserta didik untuk mengembangkan diri menjadi hasil belajar yang sama atau lebih tinggi dari yang dinyatakan dalam Standar Kompetensi Lulusan. Menyoroti salah satu peran guru dalam proses pembelajaran, yaitu sebagai perencana pembelajaran, setiap guru pada satuan pendidikan berkewajiban menyusun RPP yang lengkap dan sistematis agar pembelajaran efektif dan bermutu. Pembelajaran yang berlangsung secara efektif dan bermutu akan berimplikasi pada peningkatan mutu proses dan hasil belajar peserta didik (Ali, 2017).

Menurut Grand Design Pendidikan Karakter Kementerian Pendidikan Nasional (2010), pendidikan karakter merupakan suatu proses pembudayaan dan pemberdayaan peserta didik agar memiliki nilai-nilai luhur dan perilaku berkarakter, yang meliputi ranah olah pikir, olah hati, olah raga (kinesthetik), dan olah rasa (Nurgiansah, 2021). Pendidikan karakter menanamkan kebiasaan (habituation) tentang hal mana yang baik sehingga peserta didik menjadi paham (kognitif) tentang mana yang benar dan yang salah, mampu merasakan (afektif) nilai yang baik dan biasa melakukannya (psikomotor). Character education is a good solution to be implemented to form a strong character of the younger generation (Nurgiansah et al., 2020). Dengan kata lain, pendidikan karakter yang baik bukan hanya melibatkan aspek pengetahuan yang baik (moral knowing), akan tetapi juga merasakan yang baik (moral feeling) dan perilaku yang baik (Sunoto,2016).
Agar guru mampu menciptakan pembelajaran yang bermutu dan menyenangkan guru memiliki perencanaan pembelajaran yang komunikatif. Salah satu perangkat pembelajaran yang harus dimiliki guru adalah Rencana Pelaksanaan Pembelajaran (RPP). Seiring dengan kebijakan pemerintah dengan perlunya mengintegrasikan pendidikan budaya dan karakter bangsa (PBKB) maka guru perlu menyusun Rencana Pelaksanaan Pembelajaran (RPP) yang berkarakter atau RPP yang mengintegrasikan implementasi nilai-nilai budaya dan karakter bangsa dalam pembelajaran.(Sangat,2016).

Fenomena di lapangan yang diketahui dari hasil observasi pada tanggal 6 Juli 2019, yang dilakukan peneliti selaku Kepala SDN 3 Baturetno pada saat Kegiatan Belajar Mengajar (KBM) berlangsung, terlihat beberapa atau sebagian besar siswa belum mampu mengikuti proses pembelajaran secara optimal. Selama proses pembelajaran, potensi para siswa kurang diberdayakan sehingga sebagian besar siswa belum mampu mencapai kompetensi individual yang diperlukan untuk mengikuti pelajaran lanjutan. Beberapa siswa belum belajar sampai pada tingkat pemahaman. Siswa belum mampu mempelajari fakta, konsep, prinsip, hukum, teori, dan gagasan inovatif lainnya pada tingkat ingatan, peserta didik belum dapat menggunakan dan menerapkannya secara efektif dalam pemecahan masalah seharihari yang kontekstual.

Hasil penilaian terhadap guru-guru SDN 3 Baturetno Tahun Pelajaran 2019/2020 menunjukkan bahwa nilai ratarata kompetensi guru dalam Penguatan karakter siswa melalui PPK adalah 61,3 dengan kualifikasi C (Cukup). Artinya sebagian besar guru belum memahami pembelajaran Penguatan karakter siswa melalui PPK dan belum menerapkan pembelajaran Penguatan karakter siswa 
melalui PPK dalam kegiatan pembelajaran di kelas.

Melihat kompetensi guru yang masih rendah dalam Penguatan karakter siswa melalui PPK dan belum menerapkan pembelajaran Penguatan karakter siswa melalui PPK dalam kegiatan pembelajaran di kelas, maka peneliti sebagai kepala sekolah berencana melaksanakan suatu penelitian tindakan sekolah melalui pelaksanaan kegiatan praktik unjuk kerja. Bentuk upaya peningkatan yang digunakan dalam penelitian tindakan (action research) ini adalah praktik unjuk kerja. Metode praktik unjuk kerja adalah suatu metode dengan memberikan materi pendidikan baik menggunakan alat atau benda, seperti diperagakan, dengan harapan peserta didik menjadi jelas dan mudah sekaligus dapat mempraktikkan materi yang dimaksud suatu saat di masyarakat. Metode ini memberikan jalan kepada para peserta didik untuk menerapkan, menguji dan menyesuaikan teori dengan kondisi sesungguhnya melalui praktik peserta praktik atau latihan akan mendapatkan pelajaran yang sangat baik untuk mengembangkan dan menyempurnakan keterampilan yang diperlukan (R. Ceha, dkk., 2016: 18).

Dengan kegiatan praktik unjuk kerja diharapkan; (1) guru memahami pembelajaran Penguatan karakter siswa melalui PPK secara keseluruhan, (2) guru mengaplikasikan pembelajaran Penguatan karakter siswa melalui PPK dalam proses pembelajaran, dan (3) guru dapat meningkat kualitas kinerjanya.

\section{METODE PENELITIAN}

Penelitian ini dilaksanakan pada semester 1 tahun pelajaran 2019/2020. Tempat penelitian adalah di SD Negeri 3 Baturetno yang beralamat di Desa Belikurip, Kecamatan Baturetno, Kabupaten Wonogiri. Subjek penelitian ini adalah guru SD Negeri 3 Baturetno yang berjumlah 8 orang. Teknik dan alat pengumpulan data dalam penelitian ini yaitu dokumentasi dan lembar penilaian. Validasi data pada penelitian ini menggunakan triangulasi data yaitu berkolaborasi dengan teman sejawat yang dianggap memahami kompetensi penyusunan RPP Berkarakter dalam pembelajaran dan aplikasinya di kelas.

Langkah-langkah analisis data yang dilakukan dalam penelitian ini adalah analisa data pada penilaian kompetensi penyusunan RPP Berkarakter guru menggunakan analisis deskriptif komparatif yaitu membandingkan hasil penilaian kompetensi penyusunan RPP Berkarakter guru kondisi awal dengam nilai hasil penilaian kompetensi penyusunan RPP Berkarakter guru pada siklus I dan terakhir nilai penilaian kompetensi penyusunan RPP Berkarakter guru pada siklus II. Indikator keberhasilan penelitian tindakan ini yaitu 1) adanya peningkatan kompetensi guru dalam menyusun RPP Berkarakter dari kondisi awal ke siklus I dan dari siklus I ke siklus II, 2) ada peningkatan kualitas kinerja guru pada proses pembelajaran di kelas dari kondisi awal ke siklus I dan dari siklus I ke siklus II, serta 3) semua guru SD Negeri 3 Baturetno minimal mencapai kualifikasi Baik.

Rancangan penelitian yang digunakan adalah rancangan model Kemmis dan Taggart yang terdiri dari atas empat langkah, yakni: perencanaan, pelaksanaan, observasi dan refleksi (Arikunto, 2006: 93). Alur tindakan dalam penelitian tindakan sekolah ini dapat digambarkan sebagai berikut, 


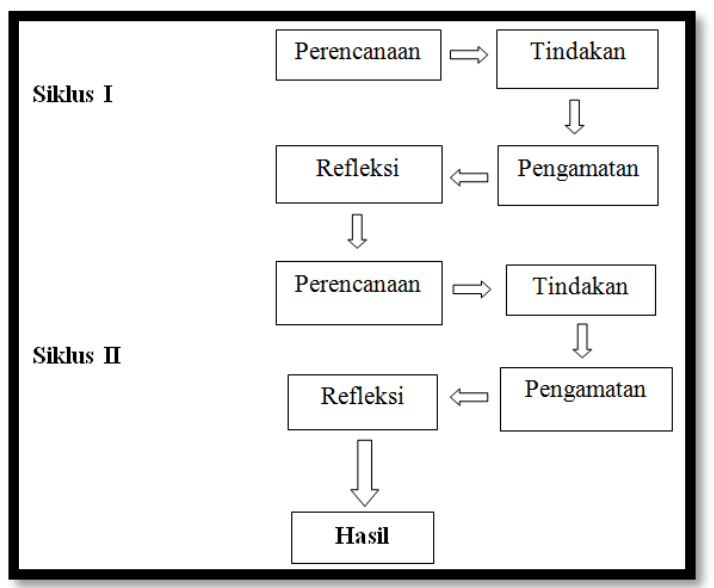

Gambar 3.1 Desain Penelitian Tindakan Sekolah

\section{HASIL PENELITIAN DAN PEMBAHASAN Hasil Penelitian \\ Deskripsi Kondisi Awal}

Berdasarkan hasil observasi pra penelitian, ditemukan fakta kompetensi guru SD Negeri 3 Baturetno Tahun Pelajaran 2019/2020 dalam memahami dan menguasai kompetensi penyusunan RPP Berkarakter dan penggunaannya pada proses pembelajaran masih rendah. Indikator rendahnya memahami dan menguasai kompetensi penyusunan RPP Berkarakter guru SD Negeri 3 Baturetno Tahun Pelajaran 2019/2020 antara lain adalah:

1. Guru belum bisa mengoperasikan komputer personal dan periferalnya termasuk melaksanakan pemograman komputer dan membuat presentasi interaktif yang memenuhi kaidah komunikasi visual dan interpersonal.

2. Guru belum mampu menyusun tujuan pembelajaran dengan memahami dan menguasai kompetensi penyusunan RPP Berkarakter sebagai media pembelajaran.

3. Guru belum mampu membuat materi ajar dengan pembelajaran dengan memahami dan menguasai kompetensi penyusunan RPP Berkarakter sebagai media pembelajaran.

4. Guru belum mampu menguraikan materi ajar dengan baik dengan memahami dan menguasai kompetensi penyusunan RPP Berkarakter sebagai media pembelajaran.

5. Guru belum mampu membuat langkahlangkah pembelajaran dengan memahami dan menguasai kompetensi penyusunan RPP Berkarakter sebagai media pembelajaran.

6. Guru belum mampu membuat penilaian sesuai dengan pembelajaran dengan memahami dan menguasai kompetensi penyusunan RPP Berkarakter sebagai media pembelajaran.

Hasil penilaian kompetensi guru SD Negeri 3 Baturetno Tahun Pelajaran 2019/2020 dalam memahami dan menguasai kompetensi penyusunan RPP Berkarakter adalah sebagai berikut.

Tabel 1. Memahami dan menguasai kompetensi penyusunan RPP Berkarakter Guru pada Kondisi Awal

\begin{tabular}{|c|c|c|}
\hline No & Predikat & Jumlah Guru (\%) \\
\hline 1 & Amat Baik & - \\
2 & Baik & 2 orang $(28,6 \%)$ \\
3 & Cukup & 4 orang $(57,1 \%)$ \\
4 & Kurang & 2 orang $(28,6 \%)$ \\
\hline \multicolumn{2}{|c|}{ Rata-rata } & 61,3 \\
& Predikat & Cukup \\
\hline
\end{tabular}

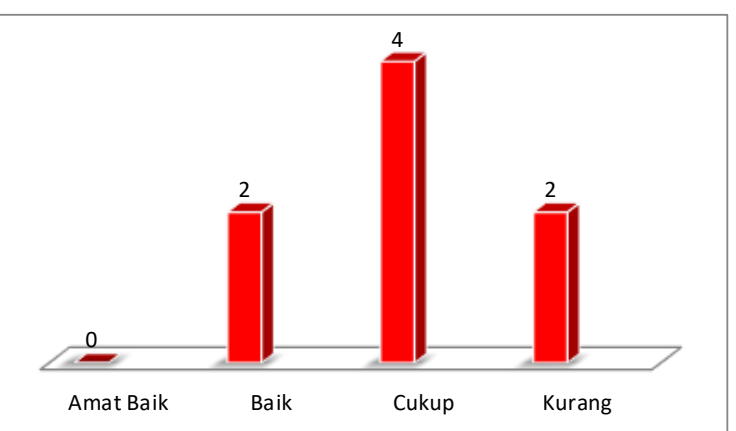

Gambar 1. Grafik Memahami dan menguasai kompetensi penyusunan RPP Berkarakter Guru pada Kondisi Awal

Mengacu pada tabel dan grafik tersebut, pada kondisi awal sebelum diterapkan praktik unjuk kerja, tidak ada guru yang masuk predikat Amat Baik, hanya 2 orang guru $(28,6 \%)$ yang masuk 
predikat Baik, 4 orang guru $(57,1 \%)$ yang masuk predikat Cukup dan masih ada 2 orang guru $(28,6 \%)$ yang masuk predikat Kurang. Nilai rata-rata kompetensi guru hanya 61,3 masuk predikat Cukup. Artinya sebagian besar guru SD Negeri 3 Baturetno belum memahami dan memahami dan menguasai kompetensi penyusunan RPP Berkarakter serta belum memahami dan menguasai kompetensi penyusunan RPP Berkarakter dalam kegiatan pembelajaran di kelas. Untuk mengatasi permasalahan rendahnya memahami dan menguasai kompetensi penyusunan RPP Berkarakter guru SD Negeri 3 Baturetno Tahun Pelajaran 2019/2020 , maka peneliti melaksankan suatu Penelitian Tindakan Sekolah (PTS) melalui penerapan praktik unjuk kerja pada siklus I.

\section{Siklus I}

Siklus I dilaksanakan dalam tiga kali pertemuan untuk pelaksanaan praktik unjuk kerja dengan program tutorial dan demonstrasi. Evaluasi dilaksanakan berupa observasi supervisi di kelas guru yang bersangkutan untuk mengetahui seberapa jauh kompetensi guru dalam memahami dan menguasai kompetensi penyusunan RPP Berkarakter. Dari hasil pengamatan terhadap aktivitas peserta dengan menggunakan lembar observasi yang telah disiapkan, diperoleh data sebagai berikut.

Tabel 2. Memahami dan menguasai kompetensi penyusunan RPP Berkarakter Guru pada Siklus I

\begin{tabular}{|c|c|c|}
\hline No & Predikat & Jumlah Guru (\%) \\
\hline 1 & Amat Baik & 2 orang $(28,6 \%)$ \\
2 & Baik & 4 orang (57,1\%) \\
3 & Cukup & 2 orang $(28,6 \%)$ \\
4 & Kurang & 0 orang (0\%) \\
\hline \multicolumn{2}{|c|}{ Rata-rata } & 78,8 \\
& Predikat & Cukup \\
\hline
\end{tabular}

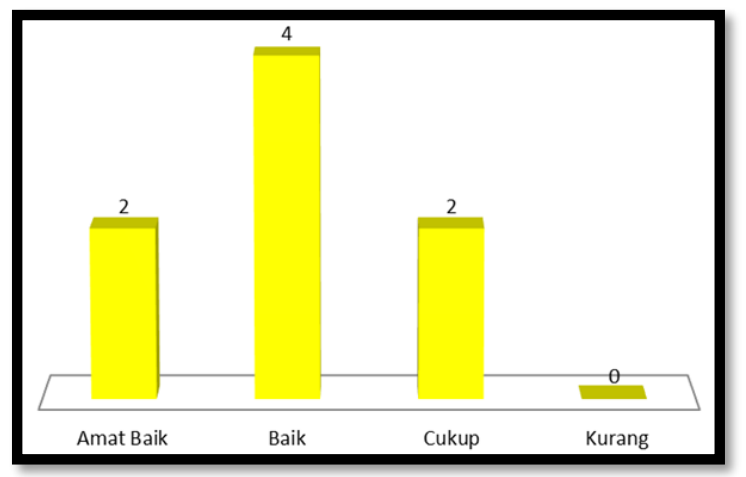

Gambar 2. Grafik Memahami dan menguasai kompetensi penyusunan RPP Berkarakter Guru pada Siklus I

Melalui pelatihan praktik unjuk kerja dapat meningkatkan memahami dan menguasai kompetensi penyusunan RPP Berkarakter guru SD Negeri 2 Belikurip. Pada siklus I ada 2 orang (28,6\%) yang masuk predikat Amat Baik, 4 orang guru (57,1 \%) yang masuk predikat Baik, 2 orang guru $(28,6 \%)$ yang masuk predikat Cukup dan masih ada 0 orang (0\%) yang masuk predikat Kurang. Nilai rata-rata kompetensi guru adalah 78,8 masuk predikat Baik. Artinya masih ada guru belum memahami dan memahami dan menguasai kompetensi penyusunan RPP Berkarakter dan belum memahami dan menguasai kompetensi penyusunan RPP Berkarakter dalam kegiatan pembelajaran di kelas. Sehingga perlu diberikan tindakan pada siklus II .

\section{Siklus II}

Siklus II dilaksanakan dalam tiga kali pertemuan untuk pelaksanaan praktik unjuk kerja dengan memahami dan menguasai kompetensi penyusunan RPP Berkarakter . Evaluasi dilaksanakan berupa observasi supervisi di kelas guru yang bersangkutan untuk mengetahui seberapa jauh kompetensi guru dalam memahami dan menguasai kompetensi penyusunan RPP Berkarakter.

Hasil penilaian memahami dan menguasai kompetensi penyusunan RPP Berkarakter guru SD Negeri 3 Baturetno 
pada siklus II diperoleh data sebagai berikut:

Tabel 3. Memahami dan menguasai kompetensi penyusunan RPP Berkarakter Guru pada Siklus II

\begin{tabular}{|c|c|c|}
\hline No & Predikat & Jumlah Guru (\%) \\
\hline 1 & Amat Baik & 3 orang (42,9\%) \\
2 & Baik & 5 orang (71,4 \%) \\
3 & Cukup & - \\
4 & Kurang & - \\
\hline \multicolumn{2}{|c|}{ Rata-rata } & 90,0 \\
& Predikat & Baik \\
\hline
\end{tabular}

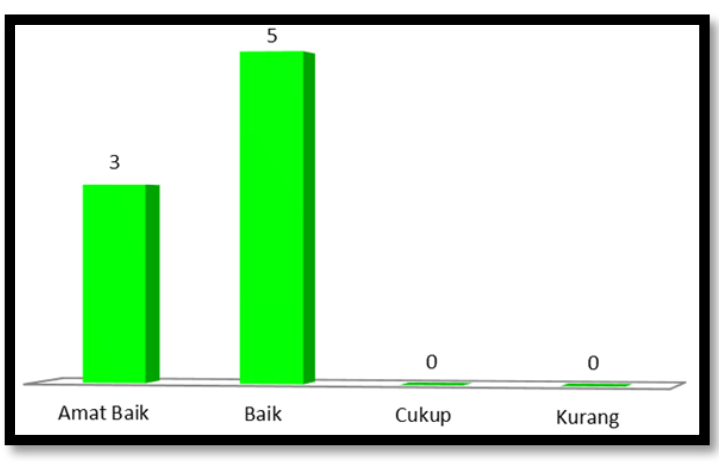

Gambar 3. Grafik Memahami dan menguasai kompetensi penyusunan RPP Berkarakter Guru pada Siklus II

Pada siklus II peneliti melaksanakan tindakan penelitian melalui pelatihan praktik unjuk kerja dengan memahami dan menguasai kompetensi penyusunan RPP Berkarakter. Pada siklus II ada 3 orang guru $(42,9 \%)$ yang masuk predikat Amat Baik, sebanyak 5 orang guru $(71,4 \%)$ yang masuk predikat Baik, dan tidak ada guru yang masuk predikat Cukup maupun Kurang. Nilai rata-rata kompetensi guru adalah 90,0 masuk predikat Baik.

Artinya semua guru sudah memahami dan memahami dan menguasai kompetensi penyusunan RPP Berkarakter dan sudah memahami dan menguasai kompetensi penyusunan RPP Berkarakter dalam kegiatan pembelajaran di kelas. Peningkatan memahami dan menguasai kompetensi penyusunan RPP Berkarakter guru SD Negeri 3 Baturetno pada siklus II sudah berhasil mencapai semua indikator kinerja penelitian sehingga tidak perlu dilanjutkan pada siklus berikutnya.

\section{Pembahasan}

RPP dijabarkan dari silabus untuk mengarahkan kegiatan belajar peserta didik dalam upaya mencapai KD (Oviana, 2013). RPP disusun untuk setiap KD yang dapat dilaksanakan dalam satu kali pertemuan atau lebih (Mahmuda, 2013). Guru merancang penggalan RPP untuk setiap pertemuan yang disesuaikan dengan penjadwalan di satuan pendidikan.

RPP berbasis karakter pada hakikatnya merupakan rencana jangka pendek untuk memperkirakan atau memproyeksikan karakter yang akan ditanamkan kepada peserta didik dalam pembelajaran (Mahmuda, 2013). Pengembangan RPP berbasis karakter harus memerhatikan minat dan perhatian peserta didik terhadap materi standar yang dijadikan bahan kajian.

Kemampuan guru untuk menyusun RPP perlu untuk ditingkatkan agar sesuai dengan kurikulum yang digunakan di sekolah. Peningkatan kemampuan guru dalam menyusun RPP dapat ditingkatkan menggunakan metode praktik unjuk kerja (Merdekawati, 2017).

Metode ini memberikan jalan kepada para peserta untuk menerapakan, menguji dan menyesuaikan teori dengan kondisi sesungguhnya melalui paktik atau kerja, inilah peserta praktik atau latihan akan mendapatkan pelajaran yang sangat baik untuk mengembangkan dan menyempurnakan keterampilan yang diperlukan (Purwasih, 2018).

Hasil penelitian ini menunjukkan bahwa Praktik unjuk kerja dapat meningkatkan kemampuan guru dalam menyusun RPP. Pada dasarnya metode ini sudah pernah digunakan oleh beberapa peneliti terdahulu. 


\section{KESIMPULAN}

Berdasarkan hasil penelitian, maka kesimpulan penelitian ini yaitu praktik unjuk kerja dapat meningkatkan kompetensi penyusunan RPP berkarakter pada guru SD Negeri 3 Baturetno Tahun Pelajaran 2019/2020.

\section{DAFTAR PUSTAKA}

Ali, M. 2017. Peningkatan Kemampuan Guru Dalam Menyusun Rencana Pelaksanaan Pembelajaran (RPP) Melalui Supervisi Akademik. Nusantara (Jurnal Ilmu Pengetahuan Sosial), Vol. 3 Desember 2017, hlm. 37-42.

Mahmuda, T. (2013). Penyusunan Rencana Pelaksanaan Pembelajaran (RPP) Guru Bhasa Indonesia di SMP N 2 BANTUL. Journal of Chemical Information and Modeling, 53(9), 1689-1699.

Merdekawati, K. (2017). Pengembangan Instrumen Penilaian Unjuk Kerja Praktikum Kimia Fisika. Paedagogia, 20(1), 24. https://doi.org/10.20961/paedagogia.v20i1.16592

Nurgiansah, T. H. (2021). Pendidikan Pancasila. In Solok: CV Mitra Cendekia Media.

Nurgiansah, T. H., Dewantara, J. A., \& Rachman, F. (2020). The Implementation of Character Education in the Civics Education Syllabus at SMA Negeri 1 Sleman. Jurnal Etika Demokrasi, 5(2), 110-121.

Oviana, W. (2013). Pengembangan Rencana Pelaksanaan Pembelajaran Berbasis Pendekatan Saintifik Oleh Guru SD dan MI di Kota Sabang. Journal of Chemical Information and Modeling, 2(9), 1689-1699.

Purwasih, W. (2018). Teknik Penilaian Unjuk Kerja dan Catatan Anekdot Sebagai Upaya Pemantauan Perkembangan Anak di PAUD Aisyiyah Cabang Kartasura Sukoharjo Jawa Tengah. Jurnal Warna, 2(2 Desember), 76-86.

R. Ceha, Endang Prasetyaningsih, Iyan Bachtiar, dan Agus Nana S. 2016. Peningkatan Kemampuan Guru Dalam Pemanfaatan Teknologi Informasi Pada Kegiatan Pembelajaran. Jurnal Managemen Pendidikan - Vol. 13, No. 1, Januari 2016: 1-1

Sunoto. 2016. upaya meningkatkan kompetensi guru dalam menyusun rencana pelaksanaan pembelajaran (rpp) berkarakter melalui supervisi akademik DI SMK N 3 Pati Sunoto SMK Negeri 3 Pati

Sangat. 2015. upaya meningkatkan kemampuan guru menyusun Rencana Pelaksanaan Pembelajaran (RPP) yang berkarakter di SD Negeri 3 Sumelap Kecamatan Tamansari UPT Dinas Pendidikan Wilayah Selatan Kota Tasikmalaya Tahun Pelajaran $2015 / 2016$

UU No. 14 Tahun 2005 Bab IV Pasal 20 (a) tentang Guru dan Dosen 